\title{
Barriers to an early switch from intravenous to oral antibiotic therapy in hospitalised
} patients with CAP

\author{
Madelon F. Engel*, Douwe F. Postma*, Marlies E.J.L. Hulscher", \\ Ferdinand Teding van Berkhout ${ }^{\dagger}$, Marielle H. Emmelot-Vonk ${ }^{+}$, Sanjay Sankatsing ${ }^{\S}$, \\ Carlo A.J.M. Gaillard ${ }^{f, * *}$, Anke H.W. Bruns ${ }^{*, f}$, Andy I.M. Hoepelman* \\ and Jan Jelrik Oosterheert*
}

ABSTRACT: Do physicians apply an early-switch strategy (from intravenous to oral antibiotics) in clinically stable patients hospitalised with community-acquired pneumonia (CAP)? If not, why not?

In a multicentre prospective cohort study, adult patients admitted for i.v. CAP treatment were included. On day 3 of antibiotic treatment, clinical stability was assessed and treating resident physicians were interviewed on their switch strategies. Additionally, treating physicians were interviewed to evaluate their knowledge of and adherence to guideline advice.

$149(92 \%)$ out of 162 patients were included and $97(91 \%)$ out of 107 physicians were interviewed. A switch to oral antibiotics was possible in $68(46 \%)$ out of 149 patients on day 3 of treatment but not performed in $27(40 \%)$ out of 68 . Patient factors delaying the switch were high CURB-65 (confusion of new onset, urea $>7 \mathrm{mmol} \cdot \mathrm{L}^{-1}$, respiratory rate of $\geqslant 30$ breaths $\cdot \mathrm{min}^{-1}$, blood pressure $<90 \mathrm{mmHg}$ or diastolic blood pressure $\leqslant 60 \mathrm{mmHg}$, and age $\geqslant 65 \mathrm{yrs}$ ) score (on admission) $(p=0.04)$ and oxygen treatment $(p=0.04)$, high temperature $(p=0.00)$ and high respiration rate $(p=0.04)$ (day 3$)$. Physicians' barriers to an early switch in clinically stable patients included misconceptions (26 (55\%) out of 47$)$, practical considerations (13 $(28 \%)$ out of 47 ) and organisational factors (eight (17\%) out of 47). Strikingly, 91 (94\%) out of 97 interviewed physicians were not aware of guideline advice.

The switch from i.v. to oral antibiotics is often unnecessarily delayed in patients hospitalised with CAP due to different types of barriers.

\section{KEYWORDS: Antibiotic treatment, community-acquired pneumonia}

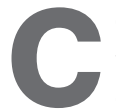

ommunity-acquired pneumonia (CAP) is the leading cause of death from infectious diseases and a substantial burden on healthcare resources in western countries [1]. Hospital admission is usually required because of intravenous antibiotic treatment, which ensures optimal tissue penetration. The i.v. therapy is often continued until patients have definitely overcome the infection [2]. A recent meta-analysis showed that an early switch to oral therapy in clinically stable patients on day $2-4$ of hospital admission, as opposed to prolonged i.v. treatment, resulted in an estimated decrease in length of hospital stay of 3.4 days and fewer medication side-effects [2]. The treatment effect, the number of recurrent infections and mortality were comparable. Even in severe forms of CAP, an early-switch strategy is usually possible on day 3 of admission [3]. Large-scale implementation of early-switch strategies would lead to a substantial reduction in healthcare costs [3, 4]. Therefore, (inter-)national guidelines advocate an early switch to oral treatment for hospitalised CAP patients $[1,5,6]$.

Despite its obvious and proven benefits, an early switch to oral therapy has not been implemented in routine clinical practice for all admitted CAP patients to date. It has been shown that healthcare staff experience barriers towards implementation of an early-switch strategy in lower respiratory tract infections due to several factors, including a
AFFILIATIONS

*Dept of Internal Medicine and Infectious Diseases, Utrecht University Medical Centre, 'Dept of Pulmonary Diseases, Utrecht University Medical Centre, ${ }^{+}$Dept of Geriatric Diseases, Utrecht University Medical Centre, and ${ }^{\text {s} D e p t ~ o f ~ I n t e r n a l ~ M e d i c i n e, ~}$ Diakonessen Hospital, Utrecht, \# Scientific Institute for Quality of Healthcare, Radboud University Medical Centre, Nijmegen, ${ }^{f}$ Dept of Internal Medicine, Meander Medical Centre, Amersfoort, and ${ }^{* *}$ Dept of Nephrology, VU University Medical Centre, Amsterdam, The Netherlands.

CORRESPONDENCE

M.F. Engel

Utrecht University Medical Centre Dept of Internal Medicine and Infectious Disease Internal mail F02.126 PO Box 85500 Utrecht The Netherlands E-mail: m.f.engel-2@umcutrecht.nl

Received:

Feb 202012

Accepted after revision: April 132012

First published online: May 312012 
perceived lack of clear guideline recommendations and a lack of outcome expectancy $[7,8]$. The level of adherence to an earlyswitch strategy (i.e. patients being switched to oral agents as soon as clinical stability is reached) in CAP is $58 \%$ on average, but varies greatly between different hospitals (22-94\%) [9]. This suggests considerable room for improvement of the adherence to an early-switch strategy.

Merely publishing results of randomised controlled trials and issuing of guidelines seems to be insufficient for implementation of an early-switch strategy in daily practice [10]. Generally, implementation strategies are ideally preceded by a proper analysis of barriers to implementation on different levels [11-13]. Therefore, we aimed to evaluate whether physicians base the conversion to oral treatment on guideline advice, what patient and physician characteristics influence the timing of the switch to oral treatment and whether physicians perceive barriers to an early-switch strategy. Identification of these barriers may form the basis of a targeted implementation strategy.

\section{METHODS}

\section{Design and setting}

In a prospective, observational, multicentre study, we evaluated the timing of the switch (i.e. cessation of i.v. antibiotics with or without conversion to oral antibiotics) and possible perceived barriers to an early-switch strategy in CAP patients admitted to internal and pulmonary medicine wards. Two teaching hospitals in the Netherlands (the Diakonessen Hospital, Utrecht, with 627 beds and the Meander Medical Centre, Amersfoort, with 982 beds) and one university hospital (Utrecht University Medical Centre, Utrecht, with 1,042 beds) participated in the study. The study protocol was approved by the local medical ethics committees. As the objective of this study was to describe physician behaviour and the main measurements were performed through physician interviews, obtaining patient informed consent was not required.

\section{Patients and procedures}

All consecutive adult patients admitted to one of the participating hospitals for i.v. CAP treatment were eligible for analysis (online supplementary appendix I). Patients were excluded if they were admitted to the intensive care unit before the switch to oral antibiotics was made or if they had a history of cystic fibrosis or lung transplantation, because prolonged i.v. treatment is often necessary in these patients. Patients with coinfections that needed immediate i.v. antibiotic treatment were excluded because of presumed interference with the duration of i.v. therapy for CAP.

In each participating centre, an investigator identified cases eligible for inclusion by screening the admission lists twice weekly and by attending the daily reports where new admissions are discussed. Usually, in the Netherlands, CAP patients needing hospitalisation are admitted to one of the wards immediately after initial evaluation in the emergency department, usually within $8 \mathrm{~h}$ of presentation. After inclusion, severity scores (CURB-65 (confusion of new onset, urea $>7 \mathrm{mmol} \cdot \mathrm{L}^{-1}$, respiratory rate of $\geqslant 30 \mathrm{breaths} \cdot \mathrm{min}^{-1}$, blood pressure $<90 \mathrm{mmHg}$ or diastolic blood pressure $\leqslant 60 \mathrm{mmHg}$, and age $\geqslant 65$ yrs) score [14] and the Pneumonia Severity Index (PSI)/Fine score [15]) and the antibiotics administered were recorded on the day of admission (day 0). As in routine practice, calculation of the CURB-65 and Fine scores was based on the available data only.

At five time-points during follow-up (day 3, 6, 14, 21 and 28 after admission), clinical patient data and the route of antibiotic administration (i.v./orally) were recorded. Clinical stability was assessed and defined as: temperature $<37.8^{\circ} \mathrm{C}$, oxygen saturation $>92 \%$ without additional administration of oxygen, stable blood pressure without the need for saline infusion or vasopressive medication, cardiac frequency $<100$ beats $\cdot \mathrm{min}^{-1}$, respiratory rate $<25$ breaths $\cdot \mathrm{min}^{-1}$ and absence of mental confusion that arose after the onset of infection [16-18]. If patients were able to swallow and were free of nausea or vomiting they were marked as "able to take oral medication". Parameters not recorded in the medical chart were assumed to be normal. Recording of clinical data ceased after a patient was switched to oral antibiotics, was discharged or died. Visits to the outpatient clinic, re-admissions and mortality were noted retrospectively 28 days after admission.

\section{Physician interviews}

Residents or senior students functioning as such, treating included patients on the third day of admission were labelled as "the treating physician" and were asked to fill out a casespecific questionnaire or were interviewed using this questionnaire (online supplementary appendix II). Generally, the resident treating a patient admitted to a ward on a specific timepoint is responsible for that patient during the entire admission. We did not record if a change in treating residents occurred during the treatment of one of the included patients because in practice this seldom occurs (e.g. when residents rotate after 6 months on a specific ward). Treating physicians were informed about the study purpose in general terms, stating that the aim was to record the physicians' motivation to choose oral or i.v. antibiotic administration. Physicians were asked whether they considered the patient to be clinically stable and if they could identify factors that influenced their choice for oral or i.v. administration of antibiotics. During the interview the researcher pointed out that factors on different levels might play a role, such as at the organisational or patient level, in order to stimulate the physicians to provide complete answers. Openended questions were used, in order to provide the opportunity to identify various barriers. Because the residents received daily supervision by medical specialists, their answers were considered a reflection of the specialist's opinion.

After the inclusion period, senior medical students, residents and supervising medical specialists involved in the treatment of included patients were invited to participate in a semistructured, in-depth interview using a physician-specific questionnaire (online supplementary appendix III). This interview addressed the physicians' general knowledge, clinical experience and opinion on the optimal timing of the switch to oral antibiotics in CAP patients. If the provided answers seemed incomplete, the physicians were encouraged to elucidate their answers. All interviews were conducted by the same investigator (M.F. Engel) in a standardised manner.

\section{Sample size calculation, outcome measurement and data analysis}

The primary outcome was the number of patients adequately switched to oral therapy on day 3 of treatment. Based on 
previous studies, a baseline adherence to an early-switch therapy in $\sim 58 \%$ of cases can be expected $[8,9]$. According to the Wilson's score interval, a sample size of 140 patients would produce a two-sided $95 \%$ confidence interval with a width equal to 0.16 when the sample proportion is 0.58 . The size of the study population was not suitable for a multilevel analysis; instead, physician and hospital characteristics were evaluated at the patient level using logistic regression analysis.

Secondary outcomes included the patient and physician factors associated with an early-switch strategy. Factors possibly associated with continuous i.v. treatment on day 3 were assessed in univariate analysis. Ratio variables were evaluated as such, and not per category (e.g. Fine score risk classes) to minimise the loss of information. Variables with a p-value $<0.05$ and with $<15 \%$ missing values were used for multivariate analysis using the forward likelihood ratio model. The goodness of fit of the model was tested with the HosmerLemeshow test. All statistical analyses were performed using SPSS version 15.0 (SPSS Inc., Chicago, IL, USA).

Remaining secondary outcomes were barriers to an earlyswitch strategy and the optimal time to switch in CAP patients in general, as perceived by the treating physicians. For these qualitative data, the frequency of specific answers provided during the interviews was calculated by counting the number of times a specific answer was provided either per case or per physician.

\section{RESULTS}

\section{Patient and physician characteristics}

Between October 2010 and May 2011, 162 patients admitted to one of the three participating hospitals were enrolled. Of the 13 $(8 \%)$ of patients who were excluded, one was excluded because he/she was transferred to another hospital, six had missing data and six were excluded for other reasons. Of the 149 included patients, one patient died before day 3; this left 148 cases for analysis (fig. 1). Overall, the mean \pm SD age was $67 \pm 17$ yrs and $71(48 \%)$ were female. $95(64 \%)$ patients had one or more comorbidities; the most frequent co-morbidities were lung disease $(n=49 ; 33 \%)$ and malignancy $(n=18 ; 12 \%)$. The mean PSI score on admission was $88 \pm 32$ (table 1). All included patients were treated on the ward to which they were initially admitted on for at least 3 days.

107 physicians were involved in the treatment of the 149 included patients and were invited for a physician-specific interview; 97 (91\%) were interviewed (fig. 1). Out of $10(9 \%)$ physicians who were excluded, four refused to participate, two were no longer working at the hospital and four were on longterm leave. Reasons for refusing participation were insufficient time in three cases and unclear in one case. The interviewed physicians consisted of $35(36 \%)$ specialists with 417.5 cumulative years of experience as a medical specialist, 53 (55\%) residents with 142.5 cumulative years of clinical experience and nine $(9 \%)$ senior students. The physicians had gained their experience in $>30$ Dutch centres and two foreign hospitals.

\section{Timing of the switch}

Overall, i.v. antibiotics were continued for $4.7 \pm 2.8$ days and the length of hospital stay was $8.2 \pm 5.5$ days (table 2 ). In 68 $(46 \%)$ out of 148 cases, a switch to oral agents was possible

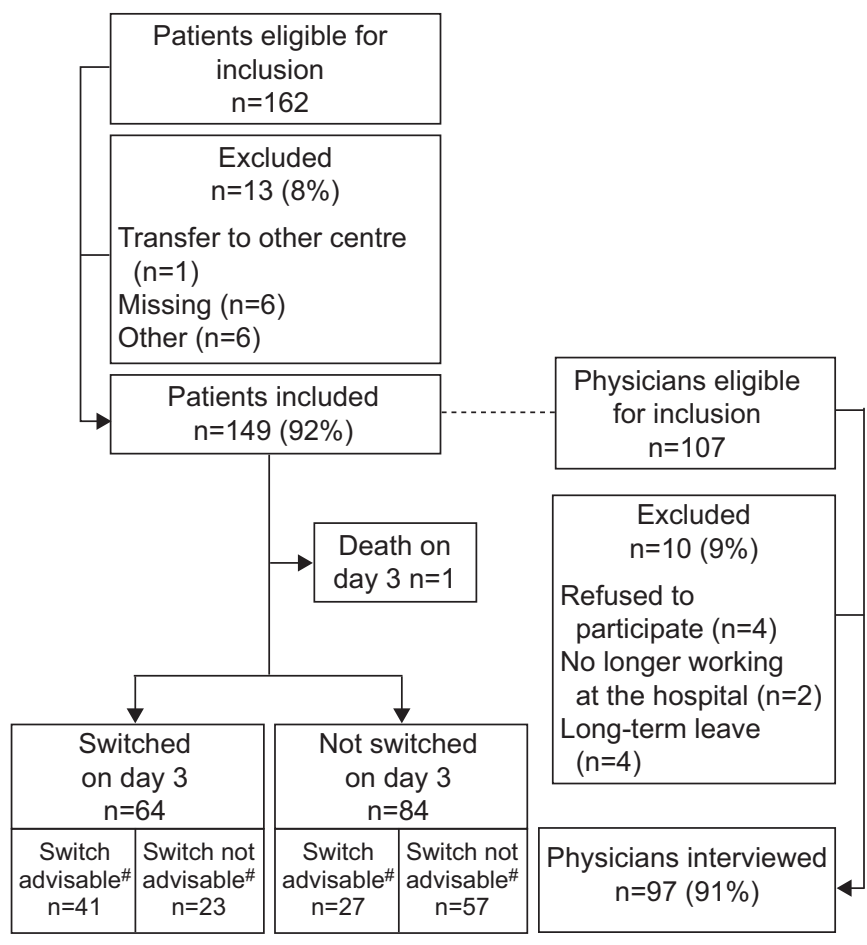

FIGURE 1. Flow chart of patients and physicians during the study. ${ }^{*}$ : patients are clinically stable and able to take medication orally.

based on the predefined clinical criteria (figs 1 and 2). However, in 27 (40\%) out of 68 cases, i.v. antibiotics were still administered on and beyond day 3 (fig. 1). The case mix on respiratory and nonrespiratory wards was comparable, aside from the higher number of comorbid lung diseases on the respiratory wards $(41(51 \%)$ out of 80 versus eight $(12 \%)$ out of $68 ; \mathrm{p}<0.00)$. The percentage of patients switched in a timely fashion was also comparable between these ward types (11 $(36 \%)$ out of 31 versus $16(43 \%)$ out of $37 ; p=0.52)$. Furthermore, the timing of the switch in the first and second half of the study $(4.9 \pm 3.2$ versus $4.5 \pm 2.5 ; p=0.38)$ was comparable, which makes a learning effect unlikely.

\section{Adherence to guideline recommendations}

Strikingly, 91 (94\%) of the 97 treating physicians were not aware of the existence of any clear guidelines on the adequate timing of the switch. Indeed, participating hospitals did not provide these guidelines through antibiotic booklets or their intranet, but there are clear (inter-)national guidelines on this subject accessible online [1]. In the physician-specific interviews, some reported switch criteria that matched the criteria used in this study, such as the absence of fever for $36(37 \%)$ physicians, declining/no need for oxygen for 24 (25\%) and haemodynamic stability for 21 $(22 \%)$ (table 3$)$. Additional factors, not matching our criteria, were a decrease in C-reactive protein for 47 (48\%) physicians and signs of clinical improvement (i.e. physician's clinical judgment or not specified) for 36 (37\%). Notably, 16 (16\%) physicians mentioned "the patient feeling better" as a criterion to switch to oral antibiotics.

Of the 116 patients marked as clinically stable by the resident (but not yet discharged) on day 3, 59 (51\%) did not meet the 


\begin{tabular}{|c|c|c|c|c|}
\hline & Total & \multicolumn{3}{|c|}{ Timing switch } \\
\hline \multicolumn{5}{|l|}{ Demographic data } \\
\hline Subjects & $148(100)$ & $64(43)$ & $84(57)$ & \\
\hline Females & $71(48.0)$ & $29(45.3)$ & $42(50.0)$ & 0.572 \\
\hline \multicolumn{5}{|l|}{ Comorbidity } \\
\hline Malignancy & $18(12.2)$ & $6(9.4)$ & $12(14.3)$ & 0.365 \\
\hline Liver disease $^{\pi}$ & $2(1.4)$ & $1(1.6)$ & $1(1.2)$ & 1.000 \\
\hline Congestive heart failure & $17(11.5)$ & $8(12.5)$ & $8(10.7)$ & 0.736 \\
\hline Cerebrovascular disease ${ }^{\llbracket}$ & $15(10.1)$ & $6(9.4)$ & $9(10.7)$ & 0.789 \\
\hline CURB-65 at presentation & $1.5 \pm 0.5$ & $1.4 \pm 1.1$ & $1.8 \pm 1.2$ & $0.046(-0.759--0.007)$ \\
\hline CURB-65 $>2$ & $34(23.0)$ & $12(18.8)$ & $22(26.2)$ & 0.286 \\
\hline Fine score at presentation & $88.4 \pm 32.0$ & $83.5 \pm 27.9$ & $92.2 \pm 34.5$ & $0.101(119.174-1.714)$ \\
\hline Fine score IV & $57(38.5)$ & $27(42.2)$ & $30(35.7)$ & 0.423 \\
\hline Fine score $\mathrm{V}$ & $11(7.4)$ & 0 & $11(13.1)$ & 0.003 \\
\hline Cough & $107(73.3)$ & $47(74.6)$ & $60(72.3)$ & 0.754 \\
\hline Sputum production & $63(45.7)$ & $30(51.7)$ & $33(41.3)$ & 0.223 \\
\hline Dyspnoea & $112(78.9)$ & $51(81.0)$ & $61(77.2)$ & 0.588 \\
\hline Temperature $>38^{\circ} \mathrm{C}$ or $<36^{\circ} \mathrm{C}$ & $92(62.2)$ & $39(60.9)$ & $53(63.1)$ & 0.789 \\
\hline Pneumonia on auscaltation & $110(74.8)$ & $54(84.4)$ & $56(67.5)$ & 0.019 \\
\hline Leukocytosis & $102(69.4)$ & $44(68.8)$ & $58(69.9)$ & 0.883 \\
\hline
\end{tabular}

Data are presented as $\mathrm{n}(\%)$ or mean $\pm \mathrm{SD}$, unless otherwise stated. Independent-sample t-tests were used for ratio variables and the Chi-squared test or Fisher's exact test for nominal variables. CURB-65: confusion of new onset, urea $>7 \mathrm{mmol} \cdot \mathrm{L}^{-1}$, respiratory rate of $\geqslant 30$ breaths $\cdot \mathrm{min}^{-1}$, blood pressure $<90 \mathrm{mmHg}$ or diastolic blood pressure $\leqslant 60 \mathrm{mmHg}$, and age $\geqslant 65 \mathrm{yrs}$; CRP: C-reactive protein. ${ }^{*}: \mathrm{n}=148$; ${ }^{\bullet}$ : as defined in the Fine score; ${ }^{+}$: missing data were not used in the calculation. Bold indicates statistical significance.

objective criteria derived from research findings. For example, some patients with high cardiac frequency (up to 182 beats. $\min ^{-1}$ ), fever (up to $39.2^{\circ} \mathrm{C}$ ) or still needing oxygen were marked as clinically stable. In contrast, some physicians noted that they did not apply an early-switch strategy in specific patients because of "fever" $\left(36.7^{\circ} \mathrm{C}\right)$ or "tachycardia" $\left(72\right.$ beats $\left.\cdot \mathrm{min}^{-1}\right)$.

\section{Barriers to an early-switch strategy}

To evaluate factors that influence the decision to convert to oral antibiotics, characteristics of the 84 (56\%) patients still on i.v. antibiotics on day 3 were compared with the $65(44 \%)$ patients on oral antibiotics (tables 1 and 2). Variables univariately associated with a prolonged duration of i.v. administration of antibiotics $(p<0.05)$ were abnormalities on auscultation suggesting pneumonia $(\mathrm{p}=0.02)$ and a high CURB-65 score $(\mathrm{p}=0.046$; 95\% CI $-0.76--0.017)$ on admission; admission to a secondary care hospital, as opposed to a university medical centre $(\mathrm{p}=0.03)$; a high respiratory frequency $(\mathrm{p}=0.04 ; 95 \% \mathrm{CI}$ -5.38- -0.08); high temperature $(p=0.00 ; 95 \%$ CI $-0.70--0.21)$; oxygen administration $(\mathrm{p}=0.01)$ and clinical instability according to the resident $(p=0.00)$ on day 3. The respiratory frequency was not recorded in $103(69 \%)$ patients, therefore this variable was excluded, and the remaining variables were used in multivariate analysis. In this analysis, nine $(6 \%)$ out of 148 patients were excluded because they were discharged on day 3 before measurements could be taken, and an additional $10(7 \%)$ had missing values because of incomplete recording. Variables that tested significant in multivariate analysis were high temperature (odds ratio 2.9, 95\% CI 1.5-5.4) and oxygen administration (OR 2.5, 95\% CI 1.8-5.5) on day 3.

As shown, patients still on i.v. antibiotics on day 3 had a higher temperature and higher respiratory frequency, and oxygen was administered more often as compared with the remaining patients. The observed mortality (due to pulmonary disease and all causes) was significantly higher in the group still receiving i.v. therapy on day $3(8 \%$ versus $0 \%, p=0.02$, and $10.7 \%$ versus $0 \%, \mathrm{p}=0.01$ ). These data suggest that patients still on i.v. antibiotics on day 3 were more severely ill. Therefore, we performed an additional analysis of patients in whom a switch was advisable on day 3 and compared the characteristics of the 27 patients who were not switched with the characteristics of the 41 patients who were adequately switched (online supplementary appendix IV). The aforementioned 27 patients 


\section{TABLE 2 Outcome measures ${ }^{\#}$}

Timing switch

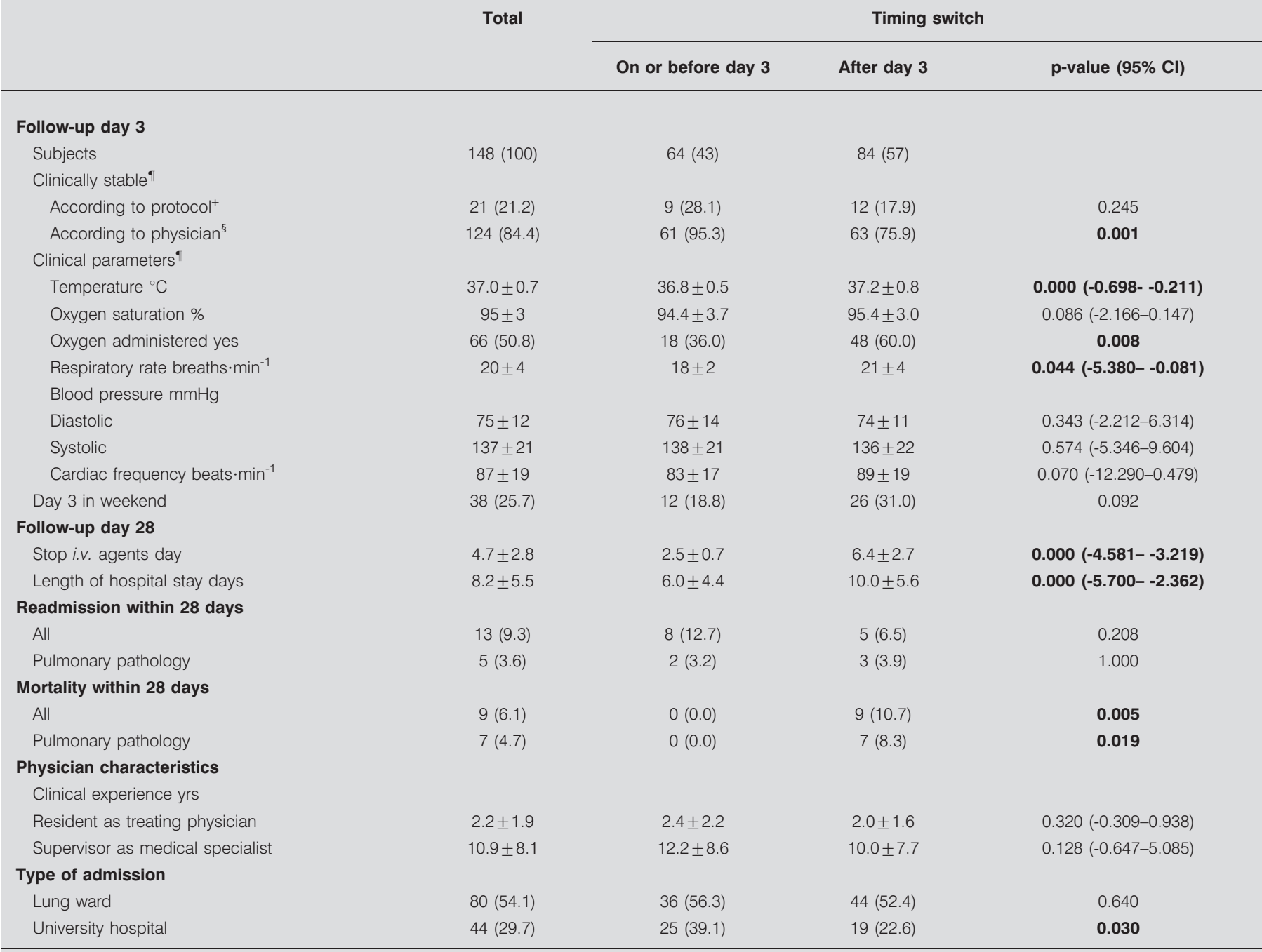

Data are presented as $n(\%)$ or mean $\pm \mathrm{SD}$, unless otherwise stated. Independent-sample t-tests were used for ratio variables and the Chi-squared test or Fisher's exact test for nominal variables. ${ }^{\#}: \mathrm{n}=148 ;{ }^{\circ}$ : missing data were not used in the calculation; ${ }^{+}$: patients discharged before day 3 were excluded; ${ }^{\S}$ : patients discharged before day 3 were marked as clinically stable according to the physician. Bold indicates statistical significance

appeared to be comparable with the patients who were adequately switched; for example, clinical parameters on day 3 and mortality rate were not significantly different.

By means of the case-specific interviews, we evaluated the barriers to a conversion to oral antibiotics. We evaluated the barriers reported by physicians treating the $27(18 \%)$ patients in whom a switch to oral antibiotics was possible but not performed (table 4). The most frequently mentioned barriers were "supervisor's opinion", "day 3 of admission was a Saturday or a Sunday" and "a switch to oral agents was possible, but forgotten"; each scenario was mentioned in five $(19 \%)$ cases. Overall, the reported barriers can be grouped into three main categories: practical considerations mentioned in 13 $(28 \%)$ out of 47 , organisational factors mentioned in eight $(17 \%)$ out of 47 and misconceptions mentioned in 28 (55\%) out of 47 .
Through the physician-specific interviews, additional theoretical barriers to an early-switch strategy were identified (table 4). Prominent discrepancies between the barriers mentioned in practice (patient-specific questionnaire) and in theory (physician-specific questionnaire) were forgetting to switch to oral agents (19\% in practice versus $2 \%$ in theory), absence of an oral variant for the administered i.v. antibiotic (18\% in theory versus $4 \%$ practice) and comorbidities delaying the switch $(22 \%$ theory versus $4 \%$ practice).

\section{DISCUSSION}

In this study, a conversion from i.v. to oral antibiotics either before or on day 3 of treatment was possible in but not performed in $27(40 \%)$ out of 68 of patients hospitalised with CAP. $94 \%$ of physicians were not aware of current guideline recommendations on the conversion to oral antibiotics. 


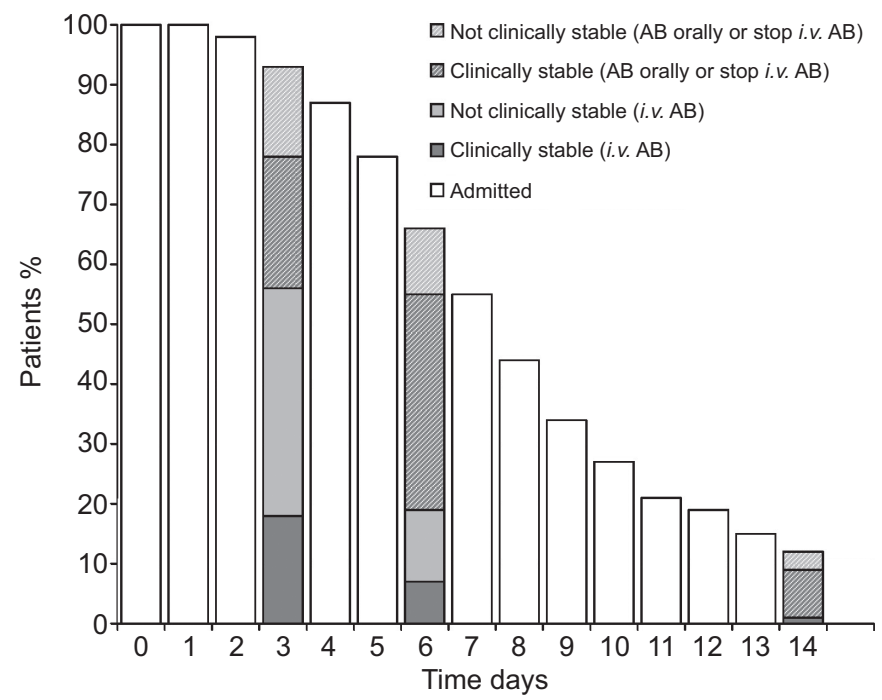

FIGURE 2. Patient stability and the route of antibiotic (AB) administration over time. i.v. intravenous.

Perceived barriers to an early-switch strategy included mainly misconceptions, practical considerations and organisational factors. It is therefore likely that the majority of the barriers identified in this study could be reduced by means of an educational intervention and structural organisational changes $[7,19]$. This may reduce the duration of i.v. antibiotic treatment and, consequently, the length of hospital stay in CAP patients.

This study has several strengths. Through intensive screening, we included all patients consecutively hospitalised with CAP in both teaching and university hospital settings. The age and sex distribution, incidence of comorbidities, severity of presentation and duration of $i . v$. therapy are comparable with other cohorts of CAP patients, which enhances the generalisability of our results $[7,19,20]$. The percentage of patients in which an appropriate switch strategy was applied in this study was comparable with the percentage found in a similar study $(60 \%$ versus 58\%) [9]. Furthermore, physicians with working experience in $>32$ different hospitals were included and reasons for nonparticipation were unlikely to have influenced study results. Reasonably, the professional experience and expertise of the participating physicians represents those of all physicians working in the same setting in the Netherlands and possibly other countries with a similar healthcare system as well [10].

There are three main drawbacks of the chosen study design. First, measuring clinical parameters on several selected days of followup as opposed to each day of admission may have led to an underestimation of the number of patients that were not switched on a timely basis, as several of these patients might had reached clinical stability before day 3 and a switch to oral agents would have been appropriate at that time. Secondly, the type of observation might have influenced study results. By asking physicians about their motivation to administer the antibiotic either i.v. or orally in specific cases at set times during the admission, their attention is drawn to the chosen treatment and they are likely to re-evaluate their choices. This phenomenon might be reflected by the notably high percentage of patients that are switched on day 3, the first day of follow-up (fig. 2).

\begin{tabular}{|c|c|c|}
\hline \multirow{2}{*}{$\begin{array}{l}\text { TABLE } 3 \\
\text { Category }\end{array}$} & \multirow[b]{2}{*}{ Qualitative answers ${ }^{\#}$} & \multirow[b]{2}{*}{$\begin{array}{c}\text { Frequency } \\
\text { n (\%) }\end{array}$} \\
\hline & & \\
\hline \multicolumn{3}{|l|}{ Clinical course } \\
\hline Clinical judgement & $\begin{array}{l}\text { Clinical improvement (clinical } \\
\text { judgement or not specified) }\end{array}$ & $36(37.1)$ \\
\hline Oral intake & $\begin{array}{l}\text { Able to swallow, no nausea, } \\
\text { vomiting or diarrhoea }\end{array}$ & $20(20.6)$ \\
\hline \multirow[t]{5}{*}{ Temperature } & Fever subsiding & 19 (19.6) \\
\hline & No fever & $36(37.1)$ \\
\hline & No fever for $\geqslant 1$ day & $7(7.2)$ \\
\hline & No fever for $\geqslant 2$ days & $6(6.2)$ \\
\hline & Other & $1(1.0)$ \\
\hline \multirow[t]{2}{*}{ Respiratory } & Dyspnoea subsiding & $16(16.5)$ \\
\hline & $\begin{array}{l}\text { Less/no need for oxygen } \\
\text { administration }\end{array}$ & $24(24.7)$ \\
\hline \multirow[t]{2}{*}{ Cardiovascular } & Haemodynamically stable & $21(21.6)$ \\
\hline & No signs of sepsis & $4(4.1)$ \\
\hline Other & & $16(16.5)$ \\
\hline \multicolumn{3}{|l|}{ Patient characteristics } \\
\hline Subjective & Patient feels better & $16(16.5)$ \\
\hline Other & & $1(1.0)$ \\
\hline \multicolumn{3}{|l|}{ Laboratory parameters } \\
\hline \multirow[t]{3}{*}{ Inflammation parameters } & Decrease in C-reactive protein & $47(48.4)$ \\
\hline & Decrease in leukocytes & $12(12.4)$ \\
\hline & Other & $2(2.0)$ \\
\hline Culture & $\begin{array}{l}\text { Pathogen known/culture } \\
\text { results available }\end{array}$ & $11(11.3)$ \\
\hline \multicolumn{3}{|l|}{ Practical considerations } \\
\hline \multirow[t]{4}{*}{ Timeline } & i.v. antibiotics, at least until day 2 & $4(4.1)$ \\
\hline & i.v. antibiotics, at least until day 3 & $17(17.5)$ \\
\hline & i.v. antibiotics, at least until day 4 & $16(16.5)$ \\
\hline & Other & $3(3.1)$ \\
\hline Choice of antibiotics & A good oral variant is available & $6(6.2)$ \\
\hline Other & & $5(5.1)$ \\
\hline
\end{tabular}

Conversely, this effect could also be caused by the general awareness of the importance of an early-switch strategy, as shown through the physician-specific questionnaires, in which a majority of physicians state that the ideal timing of the switch is either before or on day 3. However, the potential influence of the latter drawback would lead to an underestimation of the number of patients who are not switched in a timely manner and does not lessen the room for improvement in this field. Lastly, our study results may have been different if carried out in more than three hospitals. However, the number of participating physicians is quite large as compared with other studies $[7,21]$, and physicians working in a teaching hospital as well as in a university hospital setting were included. Therefore, we feel that our results adequately reflect current practice in the Netherlands.

Optimisation of antibiotic therapy in CAP by implementation of guideline advice has been the focus of attention for several years. HAGAMAN et al. [8] evaluated the effect of the implementation of American Thoracic Society guidelines on the switch to 
TABLE 4 Barriers to an early-switch strategy by case (case-specific questionnaire) and in theory (physician-specific questionnaire)

\begin{tabular}{|c|c|c|c|}
\hline \multirow[t]{2}{*}{ Factors } & \multirow[t]{2}{*}{ Qualitative answers } & \multicolumn{2}{|c|}{ Frequency } \\
\hline & & Case specific ${ }^{\#}$ & Physician specific ${ }^{\pi}$ \\
\hline \multicolumn{4}{|l|}{ Physician factors } \\
\hline & Opinion of supervisor & $5(19)$ & $13(13)$ \\
\hline & Forgot & 5 (19) & $2(2)$ \\
\hline & Other & NA & $3(3)$ \\
\hline \multicolumn{4}{|l|}{ Patient characteristics } \\
\hline \multirow[t]{4}{*}{ Patient factors } & Absorption orally not secured ${ }^{+}$ & NA & $37(38)$ \\
\hline & Comorbidity & $1(4)$ & $21(22)$ \\
\hline & Elderly patient ( $>75$ yrs) & 0 & $4(4)$ \\
\hline & Therapy adherence not secure & 0 & $4(4)$ \\
\hline \multirow{4}{*}{ Clinical course } & Fever & $3(11)$ & $6(6)$ \\
\hline & Fever subsided $<24 \mathrm{~h}$ ago & $2(7)$ & 0 \\
\hline & Dyspnoea/oxygen needed & $3(11)$ & $1(1)$ \\
\hline & Haemodynamically unstable & $2(7)$ & 0 \\
\hline \multirow[t]{7}{*}{ Additional diagnostics } & Elevated CRP & $3(11)$ & $3(3)$ \\
\hline & High leukocytes & $1(4)$ & 0 \\
\hline & Abnormalities on chest radiography & $1(4)$ & $1(1)$ \\
\hline & Confusion/delirium & 0 & $4(4)$ \\
\hline & Empyema/pleural effusion/abscess & 0 & $8(8)$ \\
\hline & Secondary infection & 0 & $4(4)$ \\
\hline & Other & NA & $11(11)$ \\
\hline Other hospital staff factors & Other & NA & $4(4)$ \\
\hline \multirow{2}{*}{ Antibiotics } & Short duration of $i . v$. therapy & $1(4)$ & 0 \\
\hline & Other & NA & $3(3)$ \\
\hline \multirow[t]{3}{*}{ Microbiology } & Culture results still unknown & $3(11)$ & $12(12)$ \\
\hline & Causative pathogen is atypical & $1(4)$ & $10(10)$ \\
\hline & Other & NA & $6(6)$ \\
\hline \multirow[t]{2}{*}{ Admission related/other } & Patient stays admitted/needs i.v. medication for other reason & 0 & $8(8)$ \\
\hline & Other & NA & $2(2)$ \\
\hline
\end{tabular}

Data are presented as $\mathrm{n}(\%)$ of cases in which an answer was provided or $\mathrm{n}(\%)$ of physicians that provided this answer, unless otherwsie stated. Answers mentioned in the physician-specific questionnaires are only displayed in detail if they were provided by $\geqslant 4$ physicians or if they were also provided in the patient-specific questionnaire; the remaining answers are provided elsewhere (supplementary appendix V). CRP: C-reactive protein; NA: not applicable. ${ }^{*}: \mathrm{n}=27 ;{ }^{\bullet}: \mathrm{n}=97 ;{ }^{+}:$e.g. $n$ ot able to swallow, nausea or vomiting. Bold indicates percentages that differ by $>10 \%$.

oral antibiotics. Unfortunately, besides assessing the guideline knowledge of physicians, practical barriers to an early-switch strategy were not studied. The implementation effect could have been greater if aimed at specifically identified barriers [11-13]. SCHOUTEN et al. [7] and HALM et al. [22] assessed barriers to an early-switch strategy in CAP patients as perceived by physicians through semi-structured interviews and written surveys, respectively. Perceived barriers to a timely switch strategy identified in these studies are also reflected by our study results, and include unfamiliarity with guideline recommendations, lack of outcome expectancy and misconceptions. In contrast to the latter studies, we are the first to compare the barriers mentioned in theory with the ones experienced in practice, completing the analysis of barriers to a timely switch strategy as 
a whole. In addition, little is currently known about the quality and quantity of the influence of patients' knowledge, behaviour and assertiveness on the antibiotic treatment regimen in hospital care [10]. Our study shows a modest role for these patientrelated factors; the switch to oral antibiotics was delayed because the patient felt ill in only one (4\%) out of 27 cases.

The results of this study stress the need for a tailored intervention aimed at the identified barriers in order to stimulate an early switch in CAP patients. The effectiveness of such an intervention needs to be evaluated in a study setting. If effective, the implementation strategy can be applied in other centres and possibly also to other types of infection. Ideally, maximal results are obtained and all patients are switched to oral antibiotics in a timely manner after implementation. Based on our study results, theoretical implementation of an earlyswitch strategy in all CAP patients in the Netherlands would lead to reduction of length of hospital stay of 3.4 days [2] in an additional $18 \%$ of patients and, consequently, to a reduction of healthcare costs of nearly €9.6 million (based on 31,000 admissions annually and $€ 505$ per admission day) [23, 24].

In conclusion, the switch from i.v. to oral antibiotics is often unnecessarily delayed in patients hospitalised with CAP; this is mostly based on misconceptions and practical and organisational issues. A tailored intervention aimed at these factors is most likely to reduce the duration of treatment with i.v. antibiotics and, consequently, length of hospital stay.

\section{SUPPORT STATEMENT}

Funding was obtained from the Netherlands Organisation for Health Research and Development (ZonMw), grant no. 171103003.

\section{STATEMENT OF INTEREST}

None declared.

\section{ACKNOWLEDGEMENTS}

We thank all participating physicians and patients.

\section{REFERENCES}

1 Mandell LA, Wunderink RG, Anzueto A, et al. Infectious Diseases Society of America/American Thoracic Society consensus guidelines on the management of community-acquired pneumonia in adults. Clin Infect Dis 2007; 44: Suppl. 2, S27-S72.

2 Athanassa Z, Makris G, Dimopoulos G, et al. Early switch to oral treatment in patients with moderate to severe communityacquired pneumonia: a meta-analysis. Drugs 2008; 68: 2469-2481.

3 Oosterheert JJ, Bonten MJ, Schneider MM, et al. Effectiveness of early switch from intravenous to oral antibiotics in severe community acquired pneumonia: multicentre randomised trial. BMJ 2006; 333: 1193.

4 Arnold FW, LaJoie AS, Brock GN, et al. Improving outcomes in elderly patients with community-acquired pneumonia by adhering to national guidelines: Community-Acquired Pneumonia Organization International cohort study results. Arch Intern Med 2009; 169: 1515-1524.

5 Schouten JA, Prins JM, Bonten MJ, et al. Revised SWAB guidelines for antimicrobial therapy of community-acquired pneumonia. Neth J Med 2005; 63: 323-335.

6 Lim WS, Baudouin SV, George RC, et al. BTS guidelines for the management of community acquired pneumonia in adults: update 2009. Thorax 2009; 64: Suppl. 3, iii1-iii55.
7 Schouten JA, Hulscher ME, Natsch S, et al. Barriers to optimal antibiotic use for community-acquired pneumonia at hospitals: a qualitative study. Qual Saf Health Care 2007; 16: 143-149.

8 Hagaman JT, Yurkowski P, Trott A, et al. Getting physicians to make "the switch": the role of clinical guidelines in the management of community-acquired pneumonia. Am J Med Qual 2005; 20: 15-21.

9 Schouten JA, Hulscher ME, Trap-Liefers J, et al. Tailored interventions to improve antibiotic use for lower respiratory tract infections in hospitals: a cluster-randomized, controlled trial. Clin Infect Dis 2007; 44: 931-941.

10 Hulscher ME, Grol RP, van der Meer JW. Antibiotic prescribing in hospitals: a social and behavioural scientific approach. Lancet Infect Dis 2010; 10: 167-175.

11 Grol R, Grimshaw J. From best evidence to best practice: effective implementation of change in patients' care. Lancet 2003; 362: 1225-1230.

12 Baker R, Camosso-Stefinovic J, Gillies C, et al. Tailored interventions to overcome identified barriers to change: effects on professional practice and health care outcomes. Cochrane Database Syst Rev 2010; 3: CD005470.

13 Grimshaw JM, Thomas RE, MacLennan G, et al. Effectiveness and efficiency of guideline dissemination and implementation strategies. Health Technol Assess 2004; 8: 1-72.

14 Lim WS, van der Eerden MM, Laing R, et al. Defining community acquired pneumonia severity on presentation to hospital: an international derivation and validation study. Thorax 2003; 58: 377-382.

15 Fine MJ, Auble TE, Yealy DM, et al. A prediction rule to identify low-risk patients with community-acquired pneumonia. $N$ Engl J Med 1997; 336: 243-250.

16 Ramirez JA, Srinath L, Ahkee S, et al. Early switch from intravenous to oral cephalosporins in the treatment of hospitalized patients with community-acquired pneumonia. Arch Intern Med 1995; 155: 1273-1276.

17 Halm EA, Fine MJ, Marrie TJ, et al. Time to clinical stability in patients hospitalized with community-acquired pneumonia: implications for practice guidelines. JAMA 1998; 279: 1452-1457.

18 Menendez R, Torres A, Rodriguez de Castro F, et al. Reaching stability in community-acquired pneumonia: the effects of the severity of disease, treatment, and the characteristics of patients. Clin Infect Dis 2004; 39: 1783-1790.

19 Barlow G, Nathwani D, Williams F, et al. Reducing door-toantibiotic time in community-acquired pneumonia: controlled before-and-after evaluation and cost-effectiveness analysis. Thorax 2007; 62: 67-74.

20 Marrie TJ, Lau CY, Wheeler SL, et al. A controlled trial of a critical pathway for treatment of community-acquired pneumonia. CAPITAL Study Investigators. Community-Acquired Pneumonia Intervention Trial Assessing Levofloxacin. JAMA 2000; 283: 749-755.

21 Barlow G, Nathwani D, Myers E, et al. Identifying barriers to the rapid administration of appropriate antibiotics in community-acquired pneumonia. J Antimicrob Chemother 2008; 61: 442-451.

22 Halm EA, Switzer GE, Mittman BS, et al. What factors influence physicians' decisions to switch from intravenous to oral antibiotics for community-acquired pneumonia? J Gen Intern Med 2001; 16: 599-605.

23 Hospital Admissions Pneumonia, Statistics Netherlands [Ziekenhuisopnamen pneummonie, Centraal Bureau voor Statistiek CBS]. http:/ / statline.cbs.nl/StatWeb/publication/?VW=T\&DM=SLNL $\& P A=71862$ ned\&LA =NL Date last accessed: October 23, 2012.

24 Hakkaart-van Roijen L, Tan SS, Bouwmans CAM. Handleiding kostenonderzoek (eng. Manual cost research) 2010. www.cvz.nl/ binaries/live/cvzinternet/hst_content/nl/documenten/lossepublicaties/handleiding-kostenonderzoek-2010.pdf Date last accessed: October 23, 2012. 